\title{
Regional Disparities in Turkey: A Socio-Economic Perspective $^{1}$
}

\author{
By Hacer Simay Karaalp-Orhan, $\mathrm{PhD*}$
}

\begin{abstract}
Economic development, for any country, is one of the most important objectives to be achieved. However, development cannot be realized in all regions and provinces of a county at the same time and speed. Turkey also struggles against a persistent economic development problem among regions in east-west and coast-inland for many years. This study aims to analyze the regional inequalities in Turkey under the scope of economic, demographic and social indicators from 2007 to the latest data. The results indicate that TR-10 Istanbul is the engine region of Turkey in terms of industrialization and development with the highest contribution (31\%) based on service and industry sectors, to the gross value added. Other industrialized regions are the Aegean region where localization economies mainly dominated and the East Marmara and TR51-Ankara regions where urbanization economies operated in. Agricultural activities heavily concentrated in Aegean, Antalya, Konya and Şanliurfa regions. In these regions, participation in the labour market is also very high. However, the highest income inequality and poverty is also found in TR10, TR62 and TR21 regions. The less developed region is the Southeast Anatolian region in terms of low income, education, health and high unemployment, young population and immigration rates.
\end{abstract}

Keywords: Regional disparities, regional development, socio-economic indicators, Turkey

\section{Introduction}

The importance of economic development as a goal to be achieved by countries started after the Second World War. However, economists and policymakers found out that development does not emerge equally in all regions of a country and concentrates on the specific regions where the suitable conditions available. Due to an unequal spatial distribution of natural and social resources; growth and development do not follow a balanced path in a country and differs in time and space (Karaalp-Gülel, 2016a:151) and therefore development disparities occur among the regions. Lagging regions are also problems of developed countries such as the European Union (EU). Many persistently low-growth regions exist in southern Europe, as do many low-income regions in Eastern Europe countries (Widuto, 2019:1). In the OECD, Turkey has the largest regional disparities in terms of GDP per capita across small regions (OECD, 2018) In addition to economic, demographic, social and geographic factors, pelitical history, cultural reasons and different political implementations can affect the economic performance of regions and thus cause regional disparities. In Turkey, as an inevitable result of the development,

1 This study was supported by Scientific Research Coordination Unit of Pamukkale University under the project number $2020 \mathrm{KKP} 004$ 
the structural transformation brings some structural problems such as shrinking of the agricultural sector in the GDP and employment, inadequate agricultural activities in the rural area, changes in the distribution of the sectoral pattern of the economy from labour to capital intensive sectors (Karaalp-Orhan and Gülel, 2016b: 49) and then clustering economic activities in specific regions and cities and thus causes the unequal distribution of investments and income inequality among sectors. Moreover, increasing rural poverty, rural-urban migration, the exclusion of the rural migrant female workforce in the city and agglomeration of the unskilled-uneducated labour force into the cities and the surge of the young population also leads to increase the unemployment rate and unregistered employment in cities (Karaalp-Orhan, 2019: 162) and thus affected the regional disparities in Turkey. In this context, the main objective of this study is to analyze the regional development disparities among NUTS -2 regions (26 sub-regions) ${ }^{2}$ in Turkey. Under this framework, regional disparities will be determined by a comparison of selected demographic, economic and social indicators for the period of 2007-2018. This paper is structured as follows. Section 2 summarize the factors that affect regional development. Section 3 compares the NUTS-2 regions according to the economic, demographic and social indicators and Section 4 concludes.

\section{Reasons for Regional Development Disparities}

Economic and social development differ in time and space. However, development cannot be realized in all regions and provinces of a county at the same time and speed due to the unequal distribution of economic and non-economic factors. In other words, regional inequalities related with regional endowments. Economic factors that play an important role in the location choice of economic units are directly related to cost-cutting factors. At the same time, these factors also related to positive externalities. Proximity to the market and raw materials which is also related with transportation costs, availability of energy and mineral sources, economic incentives and tax reductions, subsidies specific to some regions/sectors, obtaining low interest loans, easy access to technological knowledge and innovations (O’Sullivan, 2000:64), adequate physical and social infrastructure plays an essential role in the accomplishment of interregional development. Labour force (human capital) is the most important local factor that affect the development of regions. Regions where labour supply is more abundant, qualified or cheaper develop faster than the others. In order to reduce labour costs, firms will prefer to locate in the regions where labour is abundant and specialized, on the other hand, the labour force will prefer to migrate to regions where they can find jobs easily and have locational amenities (McDonald, 1997:35). Geographical characteristics are the leading factors of non-economic (indirect economic) factors. In this context, climatic conditions, landforms, topography, vegetation and soil also affected economic activities and production patterns of regions. Moderate climate and flat topography lead to development of regions by decreasing epidemics and increasing productivity (Brakman, Garretsen, and Marrewijk 2001:53). Accessibility like distance from the sea coast, natural harbours, rivers or canals also promote to reach to the international markets. Landlocked

${ }^{2}$ See Eurostat for the detail, https://ec.europa.eu/eurostat/documents/345175/7773495/TR.pdf 
economies often have lower incomes than coastal economies (Todaro and Smith, 2012: 67). Socio-cultural factors such as traditions and values are very important in terms of entrepreneurship, adaptation to innovations and inventions, encouraging or hindering social and economic activities. On the other hand, while regions' historical background affected the specialization and production habits, the political power of less developed regions and political implementations can have positive or negative effects on investments, subsidies, intensives and thus agglomeration of economic activities. Moreover, internal and external political turmoil such as international migrations, civil wars and terrorist attacks can also hinder the development of regions exposed to it. To sum up, a wide range of economic and non-economic amenities will increase the comparative advantage of regions and lead to developing them. Following these factors, industries are located particularly in certain regions creating agglomeration economies. Two views exist in the literature, related to the impact of agglomeration economies on regional development: Localizational economies are the external economies where firms of the specific industry cluster in a certain district and urbanization economies are the external economies where firms of the many different industries cluster in a certain district.

\section{Development Disparities among Regions in Turkey: An Analysis for Selected Socio-Economic Indicators}

Not only economic indicators are essential measures to analyze development, but also demographic and social indicators are also necessary to measure development. Therefore, in this study, regional differences were examined under 3 categories as, economic, demographic and social indicators.

\subsection{Economic Indicators}

During the discussion of the importance of economic development in the 1950s, economic development was measured by only economic indicators. Following the evolution of the concept of economic development, it is realized that development is not only an economic phenomenon, but it is also related to well-being and quality of life. However, it is known that it not possible to achieve development without improving economic conditions and economic growth. Industrialization is prerequisite for economic growth and development. Per capita income is the major indicator of economic development. The differences in per capita income among regions support the idea that economic activities are concentrated in certain locations. 


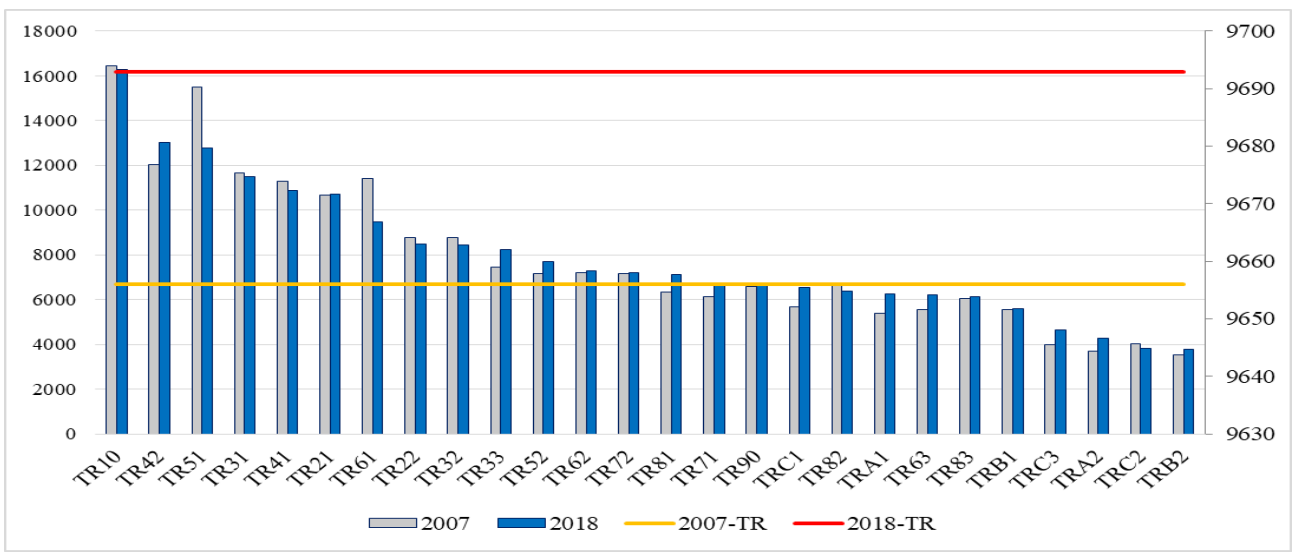

Figure 1. GDP per capita (2009 Base Year) for NUTS -2 Regions (\$). Source: TurkSTAT (2020), Regional Statistics

The most industrialized regions, TR10-Istanbul, TR42, TR51, TR31, TR41, TR21 have the highest GDP per capita, respectively. Regions in the South East and East Anatolian regions, TRB2, TRC2 and TRA2, have the lowest GDP per capita. Even though investment incentive measures, this income gap is not shrinking among the regions. GDP per capita is in TR10 region (16.264\$) is four times greater than TRB2 region (3.780\$) in 2018. While the TR10 region contributes $31 \%$ of the gross value added, TRA2 has the lowest at $0.6 \%$ in 2018.

The development includes modernization of a country's economy, society and institutions and it is also related to the structural transformation and the change of the shares of the sectors in GDP and employment of the economy. While developed regions attract more labour force due to the industrialization (opportunity to find a high wage job and a better quality of life), their contribution to the GDP is heavily based on industrial production and service sector.

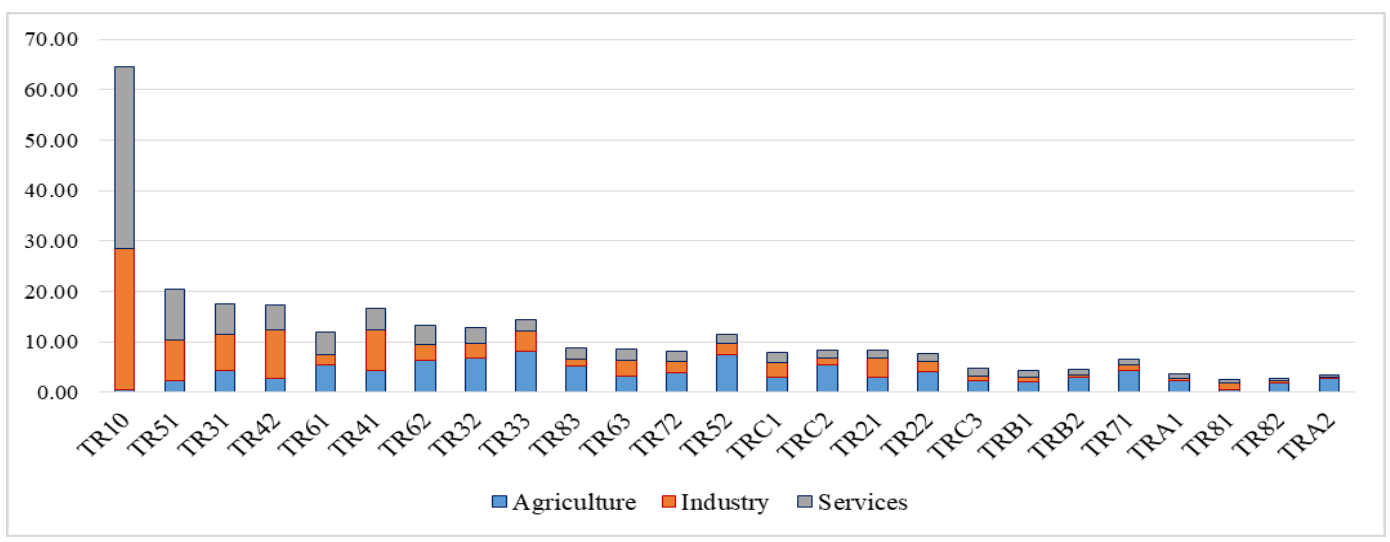

Figure 2. The Share of Economic Activity in GDP (\%) for NUTS -2 Regions in 2018.

Source: TurkSTAT (2020), Regional Statistics 
According to Figure 2, it is clear that the TR10 region has the highest contribution to GDP by services $(35.9 \%$ ) and industry $(27.9 \%)$ sectors in 2018 . While industrialized regions (TR42, TR41, TR51, TR31, TR33) located in the western part of Turkey have the greatest share of the industrial sector in GDP, they and TR61-Antalya, Isparta, Burdur region have the highest contribution in service sector. Regions where agricultural activities heavily concentrated make a high to contribution to GDP are TR33, TR52, TR32, TR62, TRC2 and TR61.

Labour market institutions are common within a country, therefore the functioning of the regional labour market is highly affected by the local (region-specific) factors that affect demand and supply of labour (Filiztekin 2009: 869). Due to the unequal distribution of economic activities among regions, the labour force spread out from less developed regions to industrial regions.

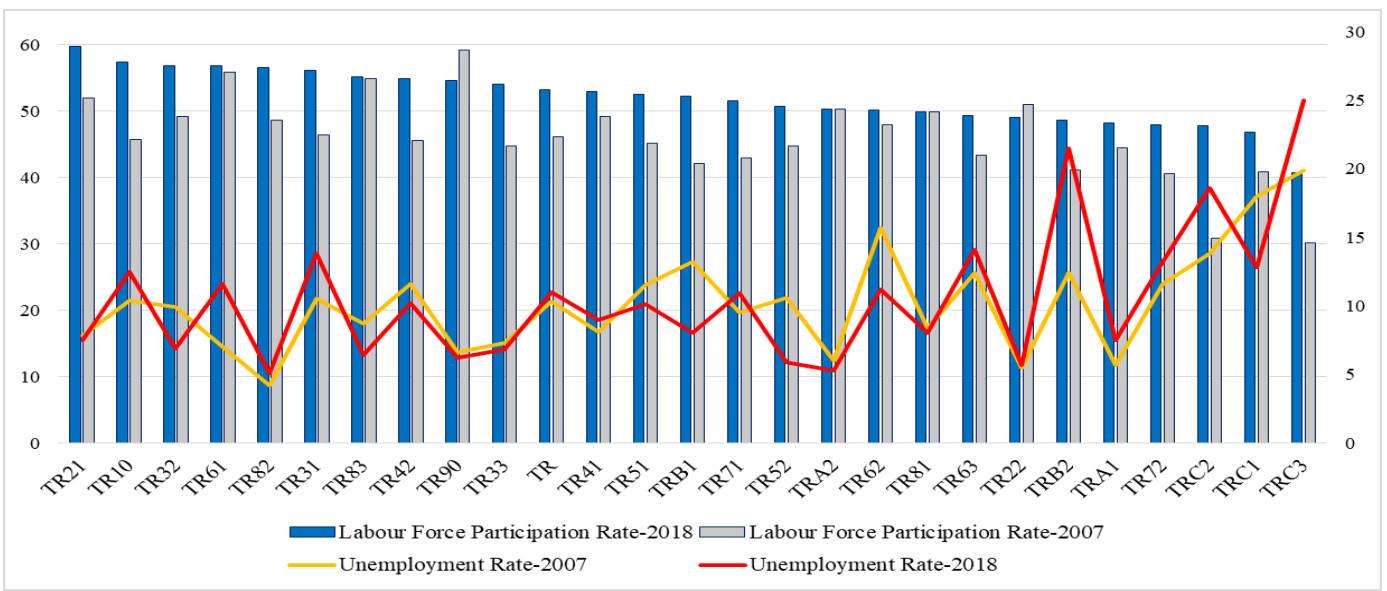

Figure 3. Labour Force Participation and Unemployment Rate for NUTS -2 Regions

Source: TurkSTAT (2020), Regional Statistics

While the low labour force participation rate (LFPR) and high unemployment rates are the two debated issues in the Turkish economy, inequalities in regional labour market indicators affected regional inequalities. The regional unemployment rate is often regarded as signposts for the socio-economic performance of regions (Cracolici et al., 2009:275). Several socio-economic factors that lie behind the regional development inequalities also cause unemployment and labour force disparities among Turkish regions.

Figure 3 shows that from 2007 to 2018, regional LFPR in Turkey increased except TR90 and TR22 regions. In 2018, LFPR is higher in TR21 (59.7\%), TR10 (57.4\%), TR32 $(56.9 \%)$ and TR61 (56.9\%) regions, where industry and service activities are intense. In the Southeast Anatolian region TRC3 (40.7\%), TRC1 (46.8\%) and TRC2 (47.8\%) LFPR is the lowest. Moreover, large and persistent regional disparities are found in unemployment rates. The highest unemployment rate is in the Southeast and Central East Anatolian regions, TRC3 (25\%), TRB2 (21.5\%) and TRC2 (18.6\%) which are far above Turkey's average (11\%) in 2018. However, the lowest unemployment rates are in TR82 (5.1\%), TRA2 (5.3\%) and TR22 (5.7\%) regions in 2018. 


\subsection{Demographic Indicators}

Researches of both economists and demographers have demonstrated a strong relationship between economic and demographic variables tending to justify the use of demographic data as indicators of economic level (Hauser, 1959:98). Population density is an important variable that reflects the development level of regions. Developed regions attract more population thus workforce due to the concentration of economic activities. On one side, the high population leads more labour supply for the economy, however, on the other side increasing crowds will cause socio-economic, environmental problems and crime.

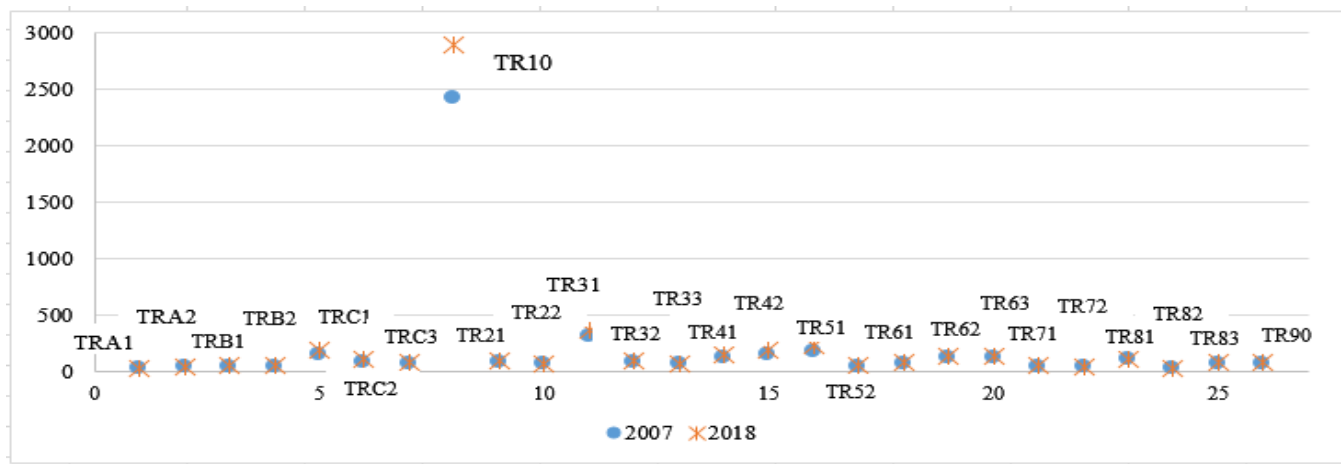

Figure 4. Population Density (people per square km)

Source: TurkSTAT (2020), Regional Statistics

High population density shows the high economic potential of regions. TR10-Istanbul region with 15.519.297 population has the highest population density among the regions over the period. Following the Istanbul region, other high populated regions are TR31, TR51, TR42, TRC1, TR41, TR63 and TR62 where economic activities are highly clustered. The lowest population density is in the eastern regions TRA1, TRA2 and inland TR82 and TR72 regions. However, according to the NUTS-3 81 provinces level, population density mostly decreases in eastern and inland provinces such as TRA11, TRA22, TRA24, TR333, TR723, TR811, TR833 in the period of 2007- 2018. There is a positive correlation between urbanization rate and economic development. Economic development based on industrialization has accompanied by urbanization and migration. The high urbanization rate is generally observed in developed countries. The high rate of urbanization in a region/country indicates that the population of the region/country mostly live in cities compared to villages. This indicates that a large part of the population is employed in industrial and service sectors where there is a relatively high value added than the agricultural sector. The main dynamics of the phenomenon of urbanization is due to the repellency of rural areas rather than the attractiveness of urban spaces. However, most of the developing countries, especially developing, come across the dilemma of big-city problems. Due to the migration of uneducated and unskilled workforce from villages to cities may cause socio-economic problems such as unemployment, poverty, inequality and living in slums. 


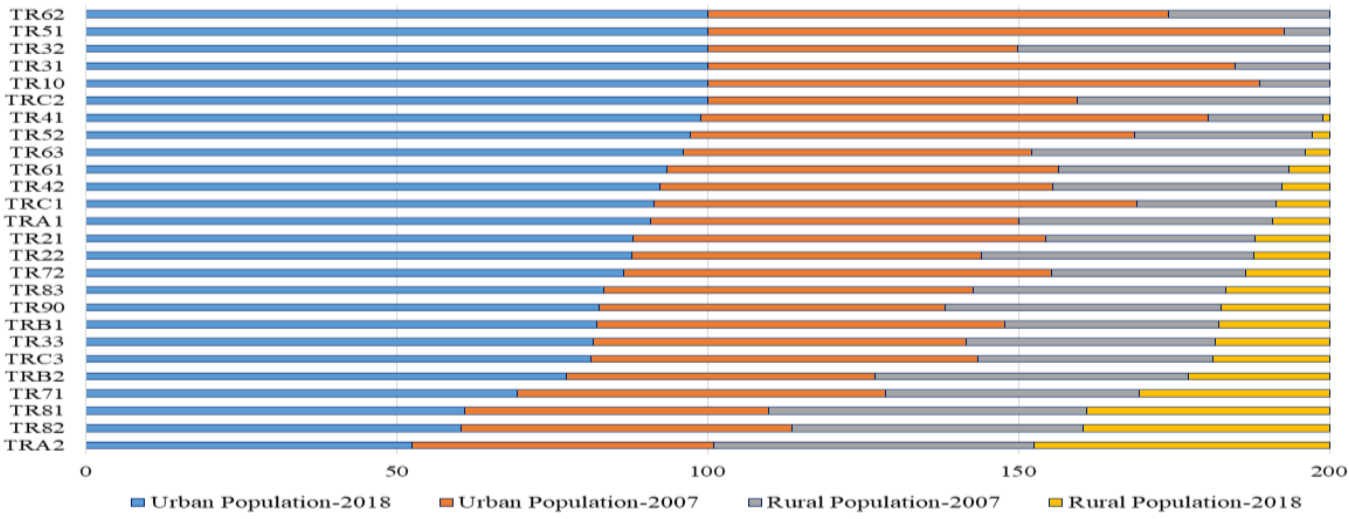

Figure 5. Rural and Urban Population (\% of Total Population) in Turkey

Source: TurkSTAT (2020), Regional Statistics

Rapid urbanization and migration from rural to urban areas in Turkey began after 1950. Throughout the development process while the rate of urbanization increase, the share of rural population decrease in Turkey. At the beginning of 1950s approximately $75 \%$ of the country's population live in rural areas (Karaalp-Orhan, 2019:165). While the share of urban population to total population was 31\% in 1960 it increased to $92 \%$ in 2018 and 2019. While the urbanization rate is the highest in the TR10, TR31, TR32, TR62 and TR51 regions, it is the lowest in the TRA2, TR81 and TR82 regions. According to the NUTS-1 regional level, while the highest urbanization rate is in the western regions (TR10, TR5, TR6, TR4 and TR3) and the lowest urbanization rate is in the northeastern regions, TRA-Northeast Anatolia (TR8 and TRB). The regions where the highest increase in urbanization rate are TR32, TR63 and TRC2 over the period of 2007-2018.

Rate of population increase is measured as the percentage yearly net relative change in population due to natural increase (where fertility and mortality rate effected) and net migration. Economic, social, cultural, educational, health and job opportunities that offered by urban area increase the attractiveness of the migration. At the beginning of the 1950s and after 1980 through industrialization, internal migration accelerated in Turkey. In one side, while migration flows from villages to cities under the process of structural transformation, in another side, due to terrorist attacks in the Eastern part of the Turkey and desire to live better conditions and a good job, internal migration has been continuing from eastern and hinterland regions to the western and coastal regions. Moreover, regions, especially in the south-east of Turkey, has been intensely exposed to international migration from Syria since at the beginning of 2000. 


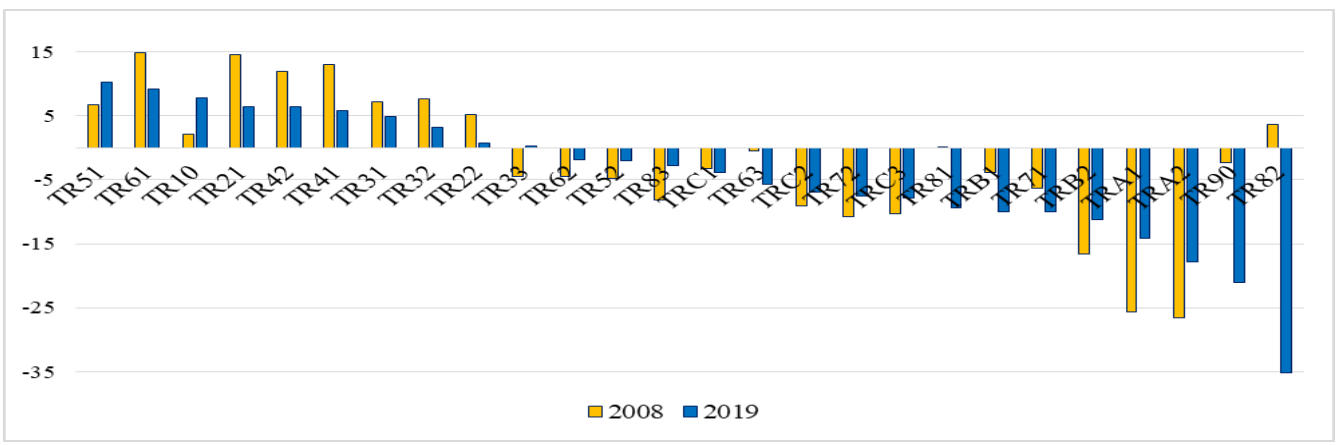

Figure 6. Net Migration Rate (\%)

Source: TurksTAT (2020), Regional Statistics

Figure 6 shows the net migration rate which indicates the contribution of migration (the difference between in-migration and out-migration) to the overall level of population change. Industrialized western regions where TR51, TR61, TR10, TR21, TR42, TR41, TR31, TR32 and TR22 have been positive net migration rate overall period. The regions with the highest immigration are TR82, TR90, TRA2, TRA1 and TRB2 in the Black Sea, Northeast and Southeast Anatolian Regions.

Dependency ratio is the measure of the age structure of a population. They relate the number of individuals that are likely to be economically "dependent" on the support of others. Dependency rate (old age and young age) provide an indication of potential social support requirements resulting from changes in population age structures. Due to fertility rate thereby population growth rate is faster in the less developed regions, youngage dependency ratio observed in the developing countries and less developed regions.

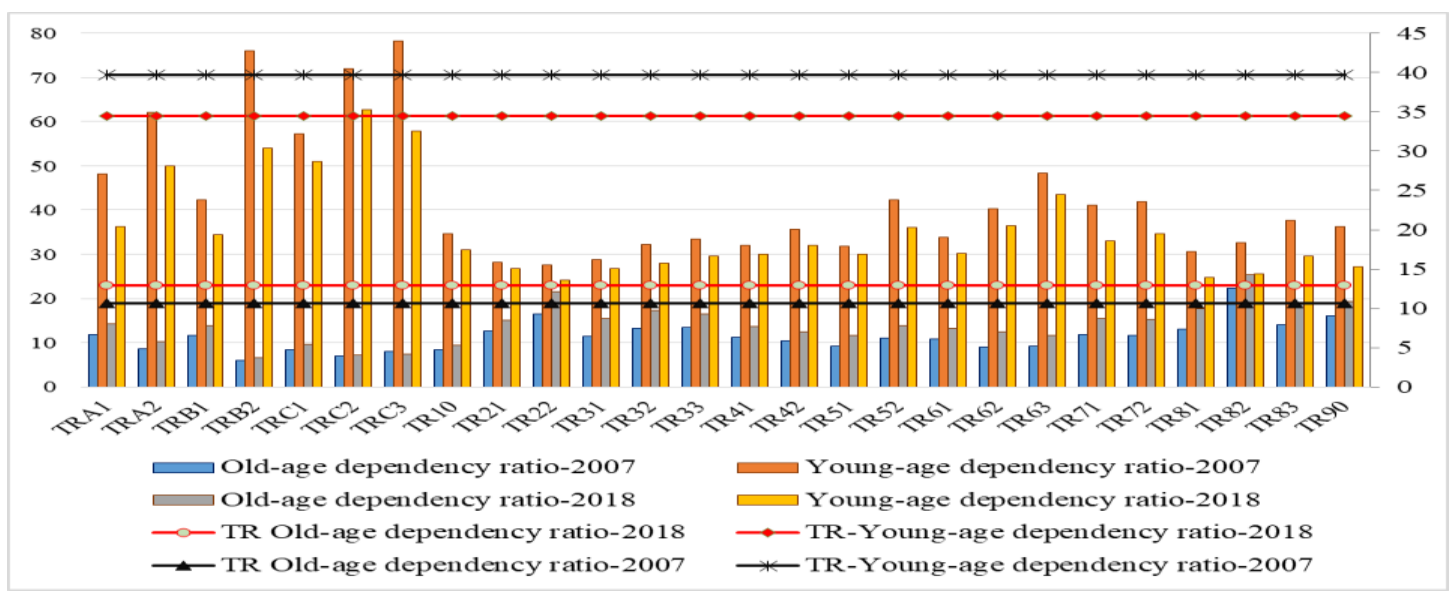

Figure 7. NUTS-2 26 Regions Old-age and Young-age Dependency Ratio (\%)

Source: TurkSTAT (2020), Regional Statistics

It is seen that as a developing country, Turkey has a high but decreasing young-age dependency ratio than old-age. While the young-age dependency ratio of Turkey was $39.71 \%$ in 2007 , it is decreased to $34 \%$ in 2018 . It is highest in the east and southeast regions of Turkey. Youth dependency ratio is the highest in the Southeast Anatolian 
Region in TRC2, TRC3, TRB2 and TRC1 regions and the lowest in TR22, TR81 and TR82 regions.

\subsection{Social Indicators}

Social indicators are concomitant with economic and demographic indicators. While social indicators affected the economic development of regions and they also being influenced by the development strategies of regions. The elimination of poverty and high and even growing income inequality are at the core of all development problems. Income inequality and poverty as an economic-based problem threatens the social structure of the regions and the country. Regional inequality is one of Turkey's structural problems and even though investment incentive measures were taken in this gap is not shrinking.

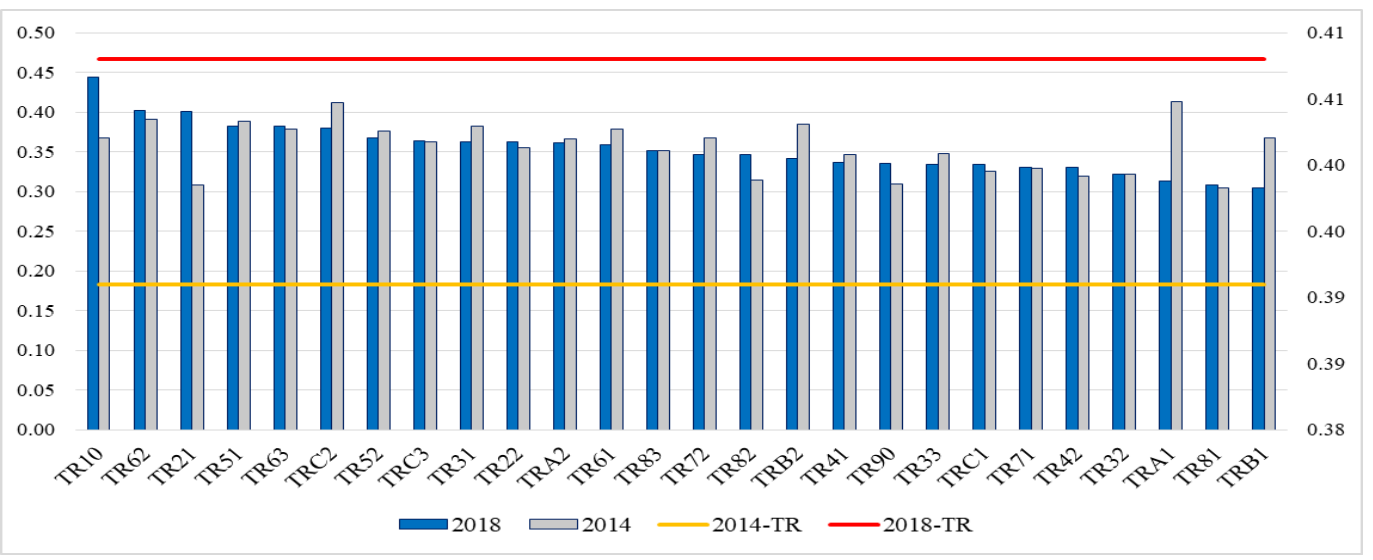

Figure 8. Gini Coefficient of NUTS -2 Regions

Source: TurkSTAT (2020), Regional Statistics

Figure 8 shows that the Gini coefficient of Turkey increase from 0.37 to 0.41 in 5 years. In 2018, the income inequality ranges between 0.44 and 0.31 among the regions. TR10, TR62 and TR21 regions have the highest Gini coefficient, above the average of Turkey in 2018. The lowest income inequality is in TRB1, TR81 and TRA1 regions, respectively. While the inequality decrease in the TRB1, TRA1, TRB2, TRC2 regions, it is increased in TR10 and TR21 regions from 2014 to 2018.

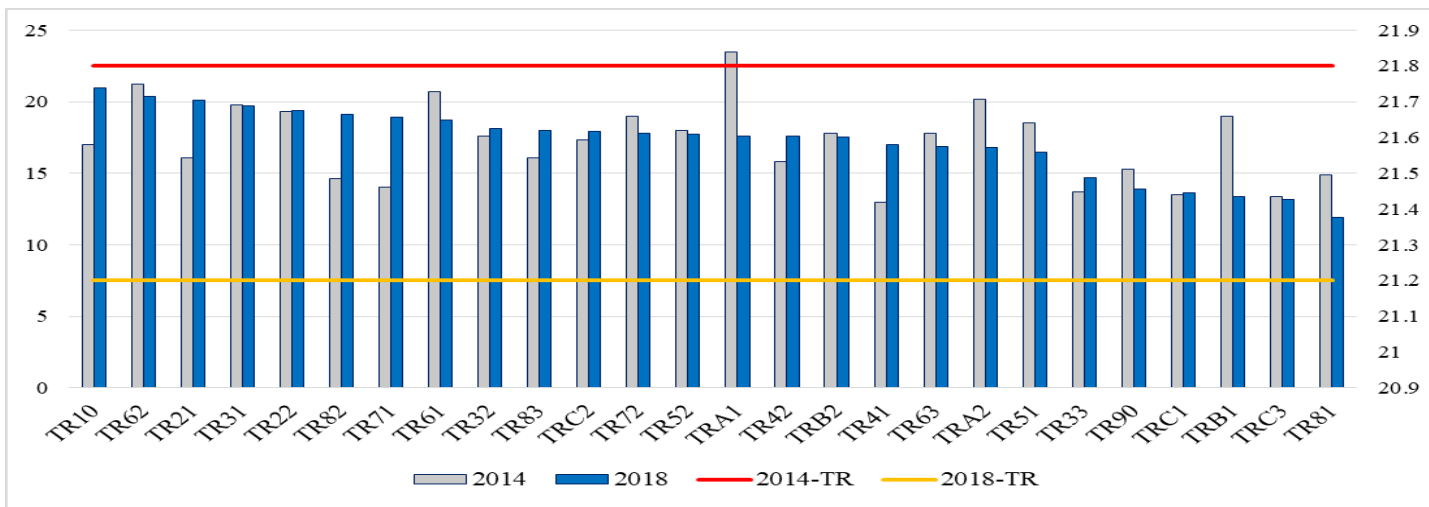

Figure 9 Poverty Rate of NUTS -2 Regions. Source: TurkSTAT (2020), Regional Statistics 
The regional poverty disparities are also another issue in the regional development of Turkey. While the average poverty rate increased from 21.4 in 2014 to 21.8 in 2018, the highest poverty observed in the eastern regions of Turkey. In 2018, the highest poverty rate is in TR10, TR62, TR21 and TR31, the lowest poverty rate is in TRB1, TRC3 and TR81 regions. Evcim, Güneş and Karaalp-Orhan (2019) also state a causal relationship between economic growth, poverty and income inequality in Turkey and among the NUTS-1 regions.

Countries that invest in quality education can realize high productivity gains and economic growth. Inadequate educational system slows down the economic growth, productivity and development. One of the causes of regional disparities in a country is the unequal spatial distribution of qualified schools over the country and having the unequal opportunities of some part of the population to access universal education. In this study, the proportion of high school or vocational school graduates to total population is used as a social indicator to measure the development differences.

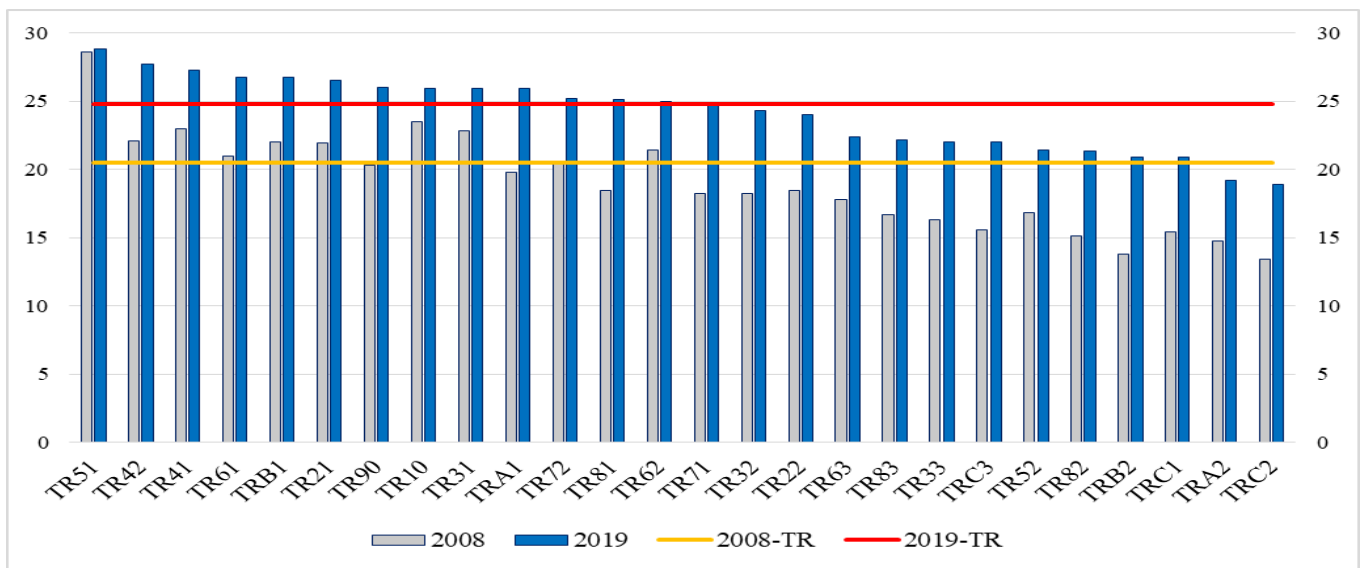

Figure 10. Proportion of High School or Vocational School Graduates to Total Population (\%) 15+ Source: TurkSTAT (2020), Regional Statistics

In the period of 2008-2019, high school graduates increased in Turkey, in 2018 the highest education level is found in the capital city Ankara-TR51, Kocaeli-TR42 and Antalya-TR61 sub-regions, respectively. However, the lowest high school graduate is in the eastern regions (TRC2 and TRC1 South East Anatolia Regions) and in North East Anatolian (TRA2) regions of Turkey.

The education and training are not the only sources of human capital but along with them, health is also an important component of human capital. They altogether boost the productivity of labour and, economic growth and reduce poverty (Karaalp-Orhan, 2018: 18). Becker (2007) considered that health and schooling behave as complements. A bilateral causal relationship occurs between economic growth/development and health. There is a strong positive correlation between health and GDP (Bloom, Kuhn and Prettner, 2018:2). Health performance and economic performance are interlinked. Countries with weak health and education conditions find it harder to achieve sustained growth and development. Wealthier countries have healthier populations for a start (Frenk, 2004). As stated with the "Preston curve" (see Preston, 1975), countries with 
better health status tend to have higher incomes than countries with worse health status. Life expectation from birth and health indicators (Number of hospital beds, number of doctors, dentists, pharmacies etc.) can be used as a proxy to measure the health performance of a country or region.

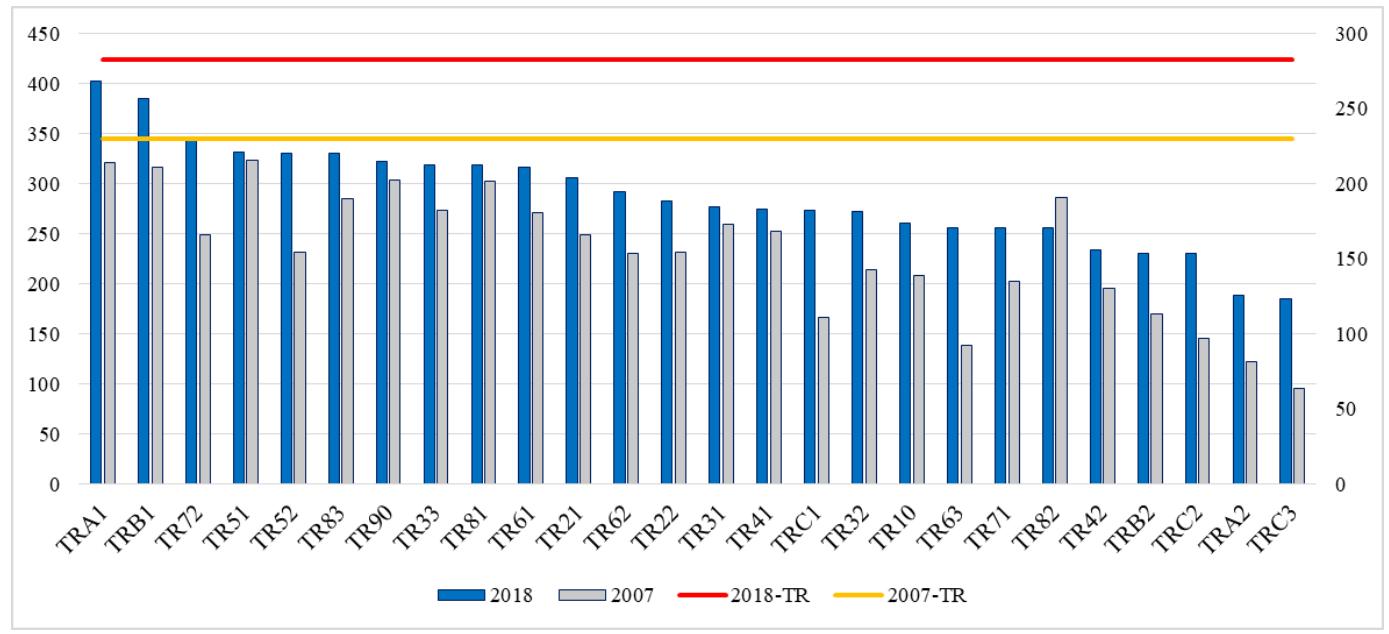

Figure 11. The Total Number of Hospital Beds per One Hundred Thousand People

Source: TurksTAT (2020), Regional Statistics

The total number of hospital beds per one hundred thousand people increase in Turkey, in this context while the highest number of beds are mainly in the Central Anatolia regions (TRA1, TRB1 and TR72) and the lowest is mainly in the Southeast Anatolia Region (TRC3, TRA2 and TRC2). The report of SEGE-2017 state that in 2019 while the developed regions located in the western part of Turkey shows the first and second stage development level, the regions and provinces, especially in the southeast part of Turkey, could not benefit enough from development amenities.

\section{Conclusion}

Economic development and growth through industrialization have been one of the fundamental policies to be achieved in Turkey. However, large and persistent regional development disparities have observed for many years. Regional inequality is one of Turkey's structural problems. Development differences across regions of Turkey are mostly observed in east-west and coast-inland. In this context, in this study regional development disparities analyzed in terms of economic, demographic and social indicators. The results indicate that, while regions and provinces in eastern and southeastern Anatolia have not been able to benefit adequately from the advantages of development, certain parts of the Black Sea and Central Anatolia regions have also lagged behind the others. First of all, the income gap is obvious among the regions. TR10 Istanbul region, where $18.4 \%$ of Turkey's population lives in, is the most important industrial distinct in Turkey. TR-10 region has the highest per capita income and it contributes $31 \%$ of the gross value added, heavily based on service and industry sectors. Secondly, other industrialized high-income NUTS-2 regions mainly spread out in the 
East Marmara, Aegean and the capital city of TR51-Ankara regions. Although urbanization rate is highest in these regions, it is also highest in the regions where agricultural activities heavily concentrated such as Aegean, Mediterranean, Konya and Şanlıurfa regions In the Mediterranean region especially TR61 region is prominent in terms of the service sector and agricultural production. LFPR is higher in the region where industry and service and agricultural activities are intense such as TR21, TR10, TR32 and TR61 regions. The high mass of migration flow to these regions, therefore, LFPR increase. However, as an inevitable result of high migration and insufficient job opportunity for overpopulation, the highest income inequality and poverty are found in TR10, TR62 and TR21 regions. On the other hand, while the South East and East Anatolian regions, TRB2, TRC2 and TRA2, have the lowest GDP per capita, LFPR is lowest in the Southeast Anatolian region. The highest unemployment rate is found in the Southeast and Central East Anatolian TRC3 (25\%), TRB2 (21.5\%) and TRC2 (18.6\%) regions. Regions with the highest immigration are Eastern and the Black Sea regions. The Southeast Anatolian region is characterized by lowest social indicators. NUTS-2 regions in the Southeast Anatolia has a high young population with lowest high school graduates and has also the lowest number of hospital beds. However, it is essential to mention that, since the provinces in NUTS-2 regional level do not exhibit a homogeneous situation in terms of socio-economic development, it is also important to evaluate the data on a provincial basis.

Due to the wide range of structural, social and cultural differences across the regions, there is no one-size-fits-all solution for Turkey. In general, lagging regions struggle with relatively low productivity and low value-added economic activities, high population growth, low educational attainment and low employment rates compared to other regions in the country. Accompanying the structural transformation of the economy, the flow of population to the developed regions cause socio-economic problems in the cities. To overcome these challenges, it is important to promote specific industries or agro-industries which are compatible with factor endowments of low-income regions. In order to converge the development of regions and to reduce the development gap, it is important to promote new growth poles and agglomeration economies in the rest of the country, instead of clustering economies in a couple of cities and regions in the western part of the country. In other words, it is essential to constitute new economic centres in the different parts of the country. In this context, to promote the localization economies in the lagged regions, it is essential to improve health and educational amenities, invest in human capital, match educational supply and labour demand, make infrastructure improvements and implement region-specific incentives, subsidies or tax allowances. However, it is important to determine the potential strategic industries or key sectors with upward and forward linkages that promote the development of neighbour regions. Moreover, to build a business-friendly environment in all over the country, it is important to improve the efficiency of public administrations, to reduce bureaucracy, to increase transparency and accountability of public services and procurements, to support judicial reforms and to support the fight against corruption, informal economy and unregistered employment. 


\section{References}

Brakman, S., Garretsen, H. and Marrewijk C. (2001), An Introduction to Geographical Economics, Cambridge: Cambridge University Press

Becker, G.S. (2007), "Health as Human Capital: Synthesis and Extensions", Oxford Economic Papers, 59(2007) :379-410.

Bloom, D.E., Michael K., and Prettner, K. (2018), Health and Economic Growth, IZA Discussion Paper Series No. 11939, Retrieved from http://ftp.iza.org/dp11939.pdf, (24.07.2020).

Cracolici, M.F., Cuffaro, M. and Nijkamp, P. (2009), "A Spatial Analysis on Italian Unemployment Differences”, Statistical Methods and Applications, 18(2): 275-291.

Evcim, N., Güneş S. and Karaalp-Orhan H.S. (2019), "The Relationship between Poverty, Inequality and Economic Growth: The Case of Nuts-1 Regions of Turkey", Journal of Management and Economics Research, 17(4):145-164.

Eurostat (2020), Statistical regions level 2 in Turkey as of 18th July 2016, Retrieved from https://ec.europa.eu/eurostat/documents/345175/7773495/TR.pdf (27.07.2020)

Filiztekin, A.(2009), "Regional Unemployment in Turkey", Papers in Regional Science, 88(4): 863-879.

Frenk, J. (2004), "Health and the economy: A vital relationship", Retrieved from https://oecdobserver.org/news/archivestory.php/aid/1241/Health and the economy: A vital relationship .html, $(24.06 .2020)$

Hauser, P.M. (1959) Demographic Indicators of Economic Development, Economic Development and Cultural Change, 7(2): 98-116.

Karaalp-Orhan H.S. and Gülel F.E. (2016a) "The Impact of the Global Financial Crises on Regional Unemployment in Turkey", International Journal of Economic Perspectives, 10(1): 151-160.

Karaalp-Orhan H.S. and Gülel F.E, (2016b) "Regional Unemployment in Turkey: A Spatial Panel Data Analysis", Journal of Social Security, 6(2): 47-67

Karaalp-Orhan, H.S. (2018), "The Impact of Gender-Specific Human Capital on Economic Growth: An Empirical Investigation for Turkey", Zagreb International Review of Economics \& Business, 21(SCI): 15-30.

Karaalp-Orhan, H.S. (2019), "Structural Transformation of the Turkish Economy under the Scope of Sustainable Development", European Journal of Sustainable Development 8 (5): 161-170.

McDonald, J. F. (1997) Fundamentals of Urban Economics, New Jersey: Prentice Hall Inc.

OECD, (2018), "Regions and Cities at a Glance 2018 - TURKEY", Retrieved from https://www.oecd.org/cfe/TURKEY-Regions-and-Cities-2018.pdf, (07.07.2020).

O'Sullivan, A. (2000) Urban Economics, Chigago: Mc Graw-Hill Higher Education

Preston, S. H. (1975), The Changing Relation Between Mortality and Level of Economic Development, Population Studies, 29(2): 231-248.

SEGE-2017, (2019), İllerin ve Bölgelerin Sosyo-Ekonomik Gelişmişlik Siralamasi Araştirmasi, Kalkınma Ajansları Genel Müdürlüğü Yayını Sayı: 3, Aralı, Ankara.

Todaro, M.P. and Smith, S.C. (2012), Economic Development, Boston:Addison-Wesley.

TurkStat (2020), Regional Statistics, Retrieved https://biruni.tuik.gov.tr/bolgeselistatistik/anaSayfa.do?dil=en ,(10.07.2020).

Widuto, A. (2019), Regional inequalities in the EU, European Parliamentary Research Service, PE 637.951, Retrieved

from, https://www.europarl.europa.eu/RegData/etudes/BRIE/2019/637951/EPRS BRI(2019)637951 EN.pdf, (26.07.2020). 